\title{
Dispatch of capacitors on distribution system using dynamic programming
}

\author{
Y.-Y. Hsu, PhD
}

H.-C. Kuo, MSc

Indexing terms: Distribution networks, Power transmission and distribution

Abstract: The dispatch of capacitors on a distribution feeder in daily system operation is investigated. The objective is to reach an optimal capacitor dispatching schedule, based on the forecast hourly loads for the next day, such that the total feeder loss in a day is minimised. The constraints that must be taken into account include the maximum allowable number of switching operations in a day for each capacitor, and the voltage limits on the feeder. An approach based on dynamic programming is presented to reach such an optimal schedule. To demonstrate the effectiveness of the proposed approach, the dispatch of capacitors on a distribution feeder within the service area of Taipei West District Office of Taiwan Power Company is investigated. It is concluded that a greater loss reduction can be achieved by the optimal capacitor dispatch than by the fixed-schedule dispatch.

List of symbole

$C_{i} \quad=$ the $i$ th capacitor installed on the feeder $S(n) \quad=$ the status for capacitor $C_{i}$ at hour $n$

$P_{n}\left[S_{1}(n), S_{2}(n), S_{3}(n), S_{4}(n)\right]=$ the feeder loss at hour $n$ when the status of capacitor $C_{i}$ at hour $n$ is $S(n)$

$P_{\text {loss }} \quad=$ the total feeder loss over the 24-hour period

$V_{j} \quad=$ voltage at bus $j$

$V^{\min } \quad \quad=$ lower limit of bus voltage

$=$ upper limit of bus voltage

$K_{i} \quad=$ the maximum allowable number of switching operations in a day for capacitor $C_{i}$

$\oplus \quad$ = exclusive $O R$ operation

$X_{n, m} \quad=$ the $m$ th capacitor state at stage $n$

$S_{l(n)}^{\prime} \quad=$ the total number of switching operations of capacitor $C_{i}$ up to stage $n$

$X_{n, m}^{\prime} \quad=$ the modified $m$ th state at stage $n$

$m_{n} \quad=$ the number of states at stage $n$

$X_{i, \text { optimat }} \quad=$ the state along the optimum path

$\bmod =$ modulo operation

$f\left(X_{n, m}^{\prime}\right) \quad=$ the minimum accumulated loss up to $X_{n, m}^{\prime}$

(C) IEE, 1993

Paper 9352C (P7), first received 30th April and in revised form 13th November 1992

The authors are with the Department of Electrical Engineering, $\mathrm{Na}$ tional Taiwan University, Taipei, Taiwan, Republic of China

IEE PROCEEDINGS-C, Vol. 140, No. 6, NOVEMBER 1993
$\left\{X_{n-1, k}^{\prime}\right\} \quad=$ the set of all feasible states that can reach $X^{\prime}$

$R\left(X_{n-1, k}^{\prime} X_{n, m}^{\prime}\right)=$ the feeder loss of state $X_{n, m}^{\prime}$

1 Introduction

Capacitors have been widely employed in distribution systems to achieve loss reduction and system capacity release, and to improve the voltage profile on a distribution feeder [1-17]. In many previous works [1-14], the capacitor placement problem has been treated as a distribution planning problem. The purpose is to determine the optimum number, location and size of shunt capacitors on distribution feeders, such that the total saving from energy loss reduction and capacity release minus the total cost of the capacitor banks installed is maximised $[2,10]$. The voltage limit on the distribution feeder is normally considered as a constraint. $A$ number of approaches such as dynamic programming $[2,7]$, analytical [8, 9], nonlinear programming [3-6, 10] and mixed integer programming $[12,13]$ have been proposed.

In contrast to the numerous reports on capacitor placement from the viewpoint of distribution system planning, work on the real-time control and dispatch of capacitors in distribution system operation has been rather limited $[2,7,15-17]$. In most of these works, the loads of feeder sections were usually assumed to change in proportion during a day. This may be due to the lack of real-time data on distribution systems. For example, the capacitors on distribution feeders of the Taiwan Power Company are normally switched on and off on a fixed schedule (capacitors are switched on during the peak hours from $8 \mathrm{a.m}$. to $6 \mathrm{p.m}$.) in daily operation. The fixed-schedule capacitor-switching strategy is by no means optimal, as the section loads as well as the total load of a distribution feeder vary with the hour of the day, day of the week and season of the year. However, the method is acceptable when the section load data are not available to system operators.

With the development of distribution automation [15, 16], feeder section loads can be continuously monitored and recorded. In addition, the capacitors can be switched on and off via a remotely controlled switch. With the availability of section load data and the capability of operating the capacitor switch in control centres, it is desirable for system operators to have a more flexible

Financial support given to this work by the National Science Council of the Republic of China under grant number NSC 81-0404-E002-004 is appreciated. 
capacitor dispatching strategy, so that greater loss reductions can be achieved in daily system operation than via the fixed-schedule dispatch.

In this paper, a novel approach based on dynamic programming is proposed to help system operators determine the optimal capacitor dispatch for the next 24 hours in daily operation. The objective is to minimise feeder losses while keeping the feeder voltage profile within prespecified limits. The number of switchings for each switchable capacitor bank is limited, based on the practical consideration of their life expectancies. In the proposed approach, any kind of load pattern in a day can be considered, provided that the load patterns have been forecast. This is the main difference between the proposed approach and previous works on capacitor placement problems [2], in which proportional loading changes during the day are assumed.

\section{Problem formulation}

Consider a distribution feeder with six sections, as shown in Fig. 1. It is assumed that the total load current of the feeder $I_{r_{(n)}}$ and section loads $I(n), i=1,2, \ldots, 6$, for the $n$th hour $(n=1,2, \ldots, 24)$ of the next day are known. These load currents can be obtained by conducting section load forecasting for the $\mathbf{2 4}$ hours of the following day $[18,19]$.

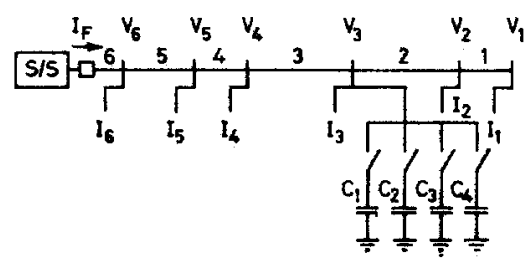

Fio. 1 A distribution feeder

A constant current load model is employed for simplicity. A more elaborate voltage-sensitive load model [14, 15] may be used if desired. The proposed approach works equally well for difierent load models. In addition, the dispatching period can be extended from 24 hours to 168 hours, or even longer, so long as accurate hourly load forecasts can be achieved.

As shown in Fig. 1, there are four switchable capacitors $C_{i}(i=1,2,3,4)$, with capacities $Q c_{i}(i=1,2,3,4)$, on the feeder. It is assumed that each capacitor can be independently switched by the operators (or computers) at the control centre via communication links. It is noted that the four capacitors are installed at the same location in Fig. 1, but the proposed method works equally well when the capacitors are placed at different locations. The capacitor dispatch problem is to determine the on/off schedule of each capacitor within the 24-hour period, such that the total loss of the feeder can be minimised. As frequent switchings may reduce the life expectancies of the switchabic capacitor banks, it is assumed that the maximum number of switching operations for each capacitor is limited.

The capacitor dispatch problem can be formulated mathematically as an optimisation problem. Let $S_{i}(n)$ $(i=1,2,3,4)$ be the status for capacitor $C_{i}$ at hour $n$, as defined below:

$$
\begin{aligned}
& S_{(}(n)=1, \text { capacitor } C_{i} \text { is on at hour } n \\
& S_{(n)}(n)=0 \text {, capacitor } C_{t} \text { is off at hour } n
\end{aligned}
$$

The optimisation problem is to determine the optimal on/off status $S_{i}(n)(i=1,2,3,4, n=1,2, \ldots, 24)$ for each capacitor $C_{i}$ at each hour $n$, such that the total feeder loss $P_{\text {lous }}$ over the 24-hour period is minimised subject to voltage limits and switching number constraints, i.e.

$$
\begin{aligned}
& \text { minimise } P_{\text {loes }}=\sum_{n=1}^{24} P_{n}\left[S_{1}(n), S_{2}(n), S_{3}(n), S_{4}(n)\right] \\
& \text { subject to } V^{\text {min }} \leqslant V_{j} \leqslant V^{\max } \quad j=1,2, \ldots, 6 \\
& \sum_{n=1}^{24} S_{(}(n) \oplus S_{(}(n-1) \leqslant K_{i} \quad i=1,2,3,4
\end{aligned}
$$

where

$P_{n}\left[S_{1}(n), S_{2}(n), S_{3}(n), S_{4}(n)\right]=$ the feeder loss at hour $n$ when the status of capacitor $C_{l}(i=1,2,3,4)$ at hour $n$ is $S(n)$

$$
\begin{aligned}
V_{j} & =\text { voltage at bus } j \\
V^{\min } & =\text { lower limit of bus voltage } \\
V^{\max } & =\text { upper limit of bus voltage } \\
K_{i} & =\text { the maximum allowable number of switching } \\
& \text { operations in a day for capacitor } C_{l} \\
\oplus= & \text { exclusive } \text { OR operation }\left[S_{S}(n) \oplus S_{S}(n-1)=1\right. \\
& \text { when } S_{(}(n) \neq S_{(}(n-1) ; \quad S_{1}(n) \oplus S_{l}(n-1)=0 \\
& \text { when } \left.S_{(}(n)=S_{l}(n-1)\right]
\end{aligned}
$$

It is noted that, in eqn. $4, S_{(0)}$ is the status of capacitor $i$ at the last hour of the preceding day. It is also noted that the constant $K_{i}$ must be specified by system operators, based on their past experience with the effect of capacitor switchings on the life expectancies of the switchable capacitor banks, switching surges, harmonics and any other practical considerations related to capacitor switchings. Here, the maximum number of switching operations is assumed to be the same for each capacitor, i.e. $K_{t}=K$ for all $i$. In current practice, a number of 2 is recommended for $K$ by the operators at the Taiwan Power Company. In other words, a capacitor which is offline at the end of the preceding day is allowed to be switched on at some time during the peak hours of the day, and switched off at some time during the offpeak period. Howrever, the optimal value for $K$ is system-dependent. The effect of the specified $K$ on the resultant total feeder loss will be examined in Section 4.

\section{Optimal capacitor dispatch using dynamic programming}

To reach the optimal capacitor switching schedule $S_{i}(n)$ $(i=1,2,3,4, n=1,2, \ldots, 24)$ which satisfies eqns. 2,3 and 4 , a dynamic programming approach can be employed. In this approach, the study period (1 day) is divided into $N$ stages ( $N=24$ here), thus, one stage is equivalent to one hour. At each stage, all possible system states are figured out. For the capacitor dispatch problem, there are 16 possible capacitor states at each stage. For example, the capacitor states at stage $n(n=1$, $2, \ldots, 24)$ are described as follows:

$$
\begin{aligned}
X_{\mathrm{a}, m}=\left[S_{1}(n), S_{2}(n), S_{3}(n), S_{4}(n)\right] \\
\quad S_{(n)}=0 \text { or } 1(i=1,2,3,4) \\
m=1,2, \ldots, 16
\end{aligned}
$$

These capacitor states are shown in the state transition diagram in Fig. 2. The initial state at stage 0 is assumed to be $X_{0,1}=(0,0,0,0)$. In other words, the four capacitors are assumed to be all switched off at the end of the preceding day.

IEE PROCEEDINGS-C, Vol. 140, NO. 6, NOVEMBER 1993 
It is observed from Fig. 2 that, starting from the source node $X_{0}, 1=(0,0,0,0)$, we need to traverse and save $\left(2^{4}\right)^{24}\left(\simeq 7.9 \times 10^{28}\right)$ possible search paths through

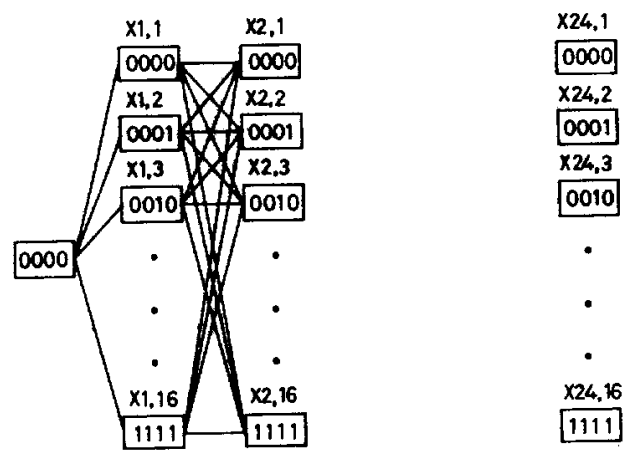

stage 0 stage 1 stage 2 - . . stage $N(=24)$ Fig. 2 State diagram and search paths for the dynamic programening approach

the system states at 24 stages. Our purpose is to find one feasible path that satisfies the constraints described in eqns. 3 and 4 , and gives the least feeder loss $P_{\text {loes }}$ over the study period. If we try to solve the problem using the state diagram and search paths in Fig. 2, we will face the difficulty of too much computer memory and intensive computational effort.

The main reason for this is the need to check whether the constraint on the number of switching operations is satisfied by a state. To do this, we have to store not only the state at the current stage, but also its source node at the preceding stage. In other words, the optimal path from a state at the current stage to the states at the next stage will depend on the source node (at the preceding stage) of that state. Thus, the paths between two states at two neighbouring stages, as well as the states, must be stored.

To reduce the computational burden, we propose to use the modified state diagram and search paths as shown in Fig. 3. The state at stage $n$ in Fig. 3 is redefined as follows:

$$
X_{n, m}^{\prime}=\left[S_{1}^{\prime}(n), S_{2}^{\prime}(n), S_{3}^{\prime}(n), S_{4}^{\prime}(n)\right]
$$

where

$$
n=1,2, \ldots, 24
$$

$S_{i}^{\prime}(n)=$ the total number of switching operations of capacitor $C_{i}$ up to stage $n$

It is obvious that the following properties are met by $S^{\prime}(n)$ :

$$
\begin{aligned}
S_{(}^{\prime}(o) & =0, i=1,2,3,4 \\
S_{(}^{\prime}(n) & -S_{(n)}^{\prime}(n-1)=0 \text { or } 1, i=1,2,3,4, n=1,2, \ldots, 24 \\
S_{(}^{\prime}(n) & \leqslant n \text { for } n \leqslant K \\
& \leqslant K \text { for } n>K
\end{aligned}
$$

where $K$ is the maximum number of switching operations for a capacitor.

It is noted that $S(n)$ in eqn. 6 is related to $S(n)$ in eqn. 5 by the following equations:

$$
\begin{aligned}
& S_{l}^{\prime}(n)=\sum_{i=1}^{n}\left|S_{i}(l)-S_{i}(l-1)\right| \\
& S_{i}(n)=\left[S_{(}^{\prime}(n) \bmod 2\right] \oplus S_{i}(o)
\end{aligned}
$$

where $S(n) \bmod 2$ is the remainder of the integer division of $S(n)$ by 2.

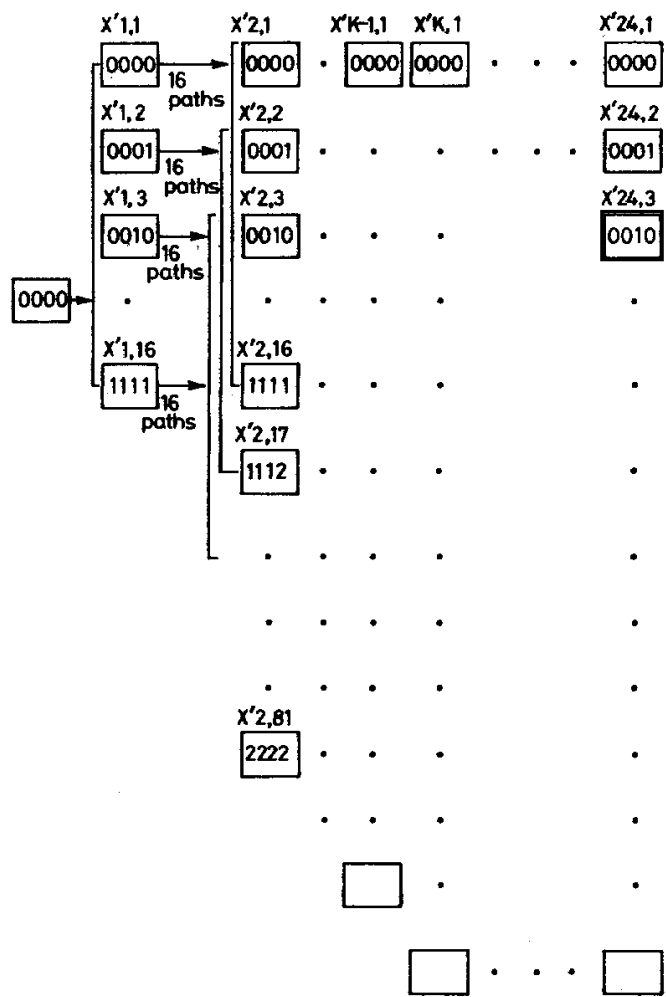

stage 0 stage 1

stoge 2 stoge $K-1$ stage $K$

stage $N(-24)$

Fig. 3 Modified state diagram and search paths for the dymonic prograwowing approach

The number of the state at stage $\boldsymbol{n}$ is given by

$$
\begin{aligned}
m_{n} & =(n+1)^{4} \quad \text { for } n<K \\
& =(K+1)^{4} \quad \text { for } n \geqslant K
\end{aligned}
$$

Using the modified state diagram in Fig. 3, the optimal capacitor dispatch schedule can be derived by solving the following recursive equation:

$$
\begin{array}{r}
f\left(X_{n, m}^{\prime}\right)=\min _{\left(X_{n-1, x)}\right.}\left[f\left(X_{k-1, n}^{\prime}\right)+R\left(X_{n-1, c}^{\prime}, X_{n, m}^{\prime}\right)\right] \\
n=1,2, \ldots, 24
\end{array}
$$

where

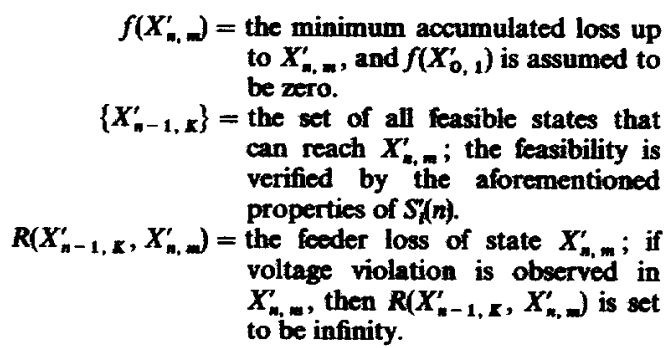

The above equation can be solved by the flow chart in Fig. 4. 
In applying the recursive formula in eqn. 10, the predecessor of a state $X_{n, m}^{\prime}$ at the $n$th stage is defined as the state $X_{n-1, x}^{\prime}$ with minimum accumulated feeder loss

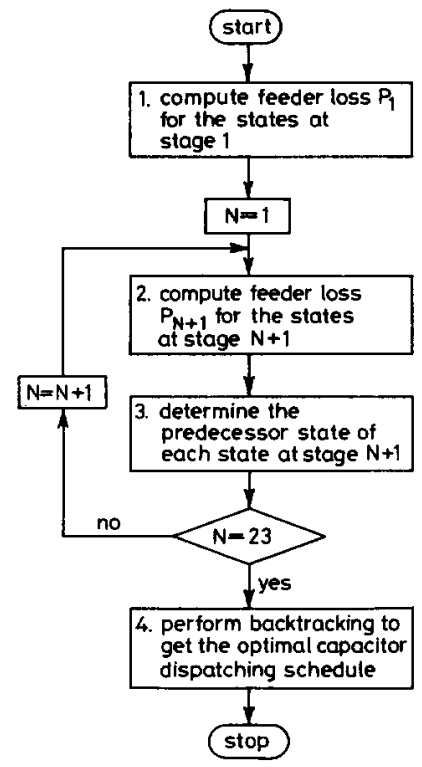

Fig. 4 Flow chart of the proposed dynamic programming algorithm for reaching the optimal capacitor dispatching schedule

$f\left(X_{n-1, x}^{\prime}\right)$ among all the states at the preceding stage $n-1$. The recursive formula begins with $n=1$, and ends with $n=24$. When the recursive computations have been performed for the states at all stages $(n=1,2, \ldots, 24)$, the state $X_{24, \text { optimal }}$ with the least accumulated feeder loss $f\left(X_{24, \text { optimal }}\right)$ among all the states at the 24th stage $(n=24)$ is chosen as the optimal state. Backtrack from this state and locate all its predecessors. The optimal capacitor dispatching schedule is then defined by these predecessors and the optimal state.

The proposed algorithm is quite efficient and requires a limited memory when the number of switchable capacitors installed on a feeder and the maximum allowable number of switching operations in a day for each capacitor are within the range for most practical systems.

The computations involved can be divided into three main parts: feeder loss calculation, predecessor determination and loss accumulation.

As there are only 16 possible capacitor combinations for each hour, we need to perform feeder loss computations $16 \times 24=384$ times. It is noted that the topology of the feeder and the locations of the capacitors affect only the time required for feeder loss computations. The computational complexity of the proposed algorithm depends mainly on the number of switchable capacitors installed on the feeders.

To improve the efficiency of predecessor determination, the states $X_{n-1,}^{\prime}$ at stage $n-1$ are ranked according to the minimum accumulated losses $f\left(X_{n-1, k}^{\prime}\right)$ first. The $X_{n-1,}^{\prime} \mathrm{K}$ with least $f\left(X_{n-1, n}^{\prime}\right)$ is assigned as the predecessor of the 16 possible $X_{n, m}^{\prime}$ that can be reached by $X_{n-1, x}^{\prime}$, according to the properties of $S_{(}^{\prime}(n)$. If $X_{n, m}^{\prime}$ has a predecessor already, the predecessor assignment is dis- carded. The number of times the predecessor assignment process needs to be repeated is

$$
16 \times\left[\sum_{n=1}^{K-1}(n+1)^{4}+\sum_{n=K}^{24}(K+1)^{4}\right]
$$

Also, it is observed that, for each state at stage $n$, we need to save the loss $P_{n}$ and the accumulated loss $P_{1}+P_{2}$ $+\cdots+P_{n}$ for that state and its predecessor state at stage $n-1$. Thus, from eqn. 9 , the total number of states that must be stored is

$$
\sum_{n=1}^{K-1}(n+1)^{4}+\sum_{n=K}^{24}(K+1)^{4}
$$

If we allow each capacitor to be switched twice at most $(K=2)$, then the total number of states is $2^{4}+23 \times 3^{4}=1879$.

\section{Example}

Consider the distribution feeder as shown in Fig. 1. The line data and capacitor data, compiled from the Taipei West District Office of the Taiwan Power Company, are shown in Table 1 and Table 2, respectively. The forecast section loads for the 24 hours of the next day are given in Table 3.

Table 1 : Line date

\begin{tabular}{lllllll}
\hline Section & 1 & 2 & 3 & 4 & 5 & 6 \\
\hline Length $(\mathrm{km})$ & 1.8 & 2.8 & 3.0 & 1.2 & 2.2 & 0.8 \\
Resistance $(\Omega / \mathrm{km})$ & 0.131 & 0.131 & 0.131 & 0.131 & 0.131 & 0.0901 \\
Reactance $(\Omega / \mathrm{km})$ & 0.391 & 0.391 & 0.391 & 0.391 & 0.391 & 0.199 \\
\hline
\end{tabular}

Table 2: Capacitor data

\begin{tabular}{lllll}
\hline Capacitor & $C_{1}$ & $C_{2}$ & $C_{3}$ & $C_{4}$ \\
\hline Rated capacity (KVAR) & 900 & 600 & 300 & 300 \\
\hline
\end{tabular}

\begin{tabular}{|c|c|c|c|c|c|c|c|}
\hline Hour & $\begin{array}{l}\text { Total } \\
\text { current }\end{array}$ & $\begin{array}{l}\text { Section } \\
1\end{array}$ & $\begin{array}{l}\text { Section } \\
2\end{array}$ & $\begin{array}{l}\text { Section } \\
3\end{array}$ & $\begin{array}{l}\text { Section } \\
4\end{array}$ & $\begin{array}{l}\text { Section } \\
5\end{array}$ & $\begin{array}{l}\text { Section } \\
6\end{array}$ \\
\hline 1 & 29.17 & 4.17 & 8.33 & 3.33 & 3.75 & 6.46 & 3.13 \\
\hline 2 & 23.75 & 2.92 & 7.08 & 2.92 & 2.92 & 5.00 & 2.92 \\
\hline 3 & 24.38 & 6.25 & 6.25 & 2.50 & 2.71 & 4.17 & 2.50 \\
\hline 4 & 21.04 & 5.42 & 6.42 & 2.08 & 2.71 & 3.33 & 2.08 \\
\hline 5 & 45.42 & 7.92 & 10.00 & 7.92 & 5.83 & 5.83 & 7.92 \\
\hline 6 & 87.50 & 14.58 & 12.50 & 14.58 & 14.58 & 14.58 & 16.67 \\
\hline 7 & 134.58 & 24.17 & 22.08 & 24.17 & 20.00 & 20.00 & 24.17 \\
\hline 8 & 168.75 & 29.17 & 27.08 & 27.08 & 27.08 & 29.17 & 29.17 \\
\hline & 212.60 & 36.42 & 33.33 & 35.42 & 37.50 & 37.50 & 33.33 \\
\hline 10 & 242.50 & 38.33 & 42.50 & 40.42 & 40.42 & 38.33 & 42.50 \\
\hline 11 & 270.83 & 45.83 & 45.83 & 43.75 & 45.83 & 43.76 & 45.83 \\
\hline 12 & 212.50 & 37.50 & 37.50 & 33.33 & 33.33 & 33.33 & 37.50 \\
\hline 13 & 262.50 & 43.75 & 43.76 & 43.75 & 45.83 & 41.67 & 43.75 \\
\hline 14 & 255.00 & 42.50 & 42.50 & 42.50 & 42.50 & 42.50 & 42.50 \\
\hline 15 & 236.25 & 40.42 & 38.33 & 38.33 & 38.33 & 40.42 & 40.42 \\
\hline 16 & 218.75 & 37.50 & 35.42 & 35.42 & 35.42 & 37.50 & 37.50 \\
\hline 17 & 136.25 & 25.83 & 21.67 & 21.67 & 23.75 & 21.67 & 21.67 \\
\hline 18 & 148.75 & 25.83 & 23.75 & 23.75 & 25.83 & 25.83 & 23.75 \\
\hline 19 & 156.67 & 27.50 & 25.42 & 23.33 & 27.50 & 27.50 & 25.42 \\
\hline 20 & 156.25 & 25.00 & 25.00 & 25.00 & 27.08 & 27.08 & 27.08 \\
\hline 21 & 167.60 & 30.00 & 25.83 & 30.00 & 25.83 & 25.83 & 30.00 \\
\hline 22 & 119.58 & 21.67 & 19.58 & 21.67 & 19.58 & 19.58 & 17.50 \\
\hline 23 & 85.42 & 16.67 & 16.67 & 12.50 & 14.58 & 12.50 & 12.50 \\
\hline 24 & 42.92 & 7.08 & 9.17 & 7.50 & 9.17 & 5.00 & 5.00 \\
\hline
\end{tabular}

Table 3: Forecasted hourly load currents (A)

Based on these data, we can calculate the feeder losses $P_{n, m}$ for each possible capacitor state $X_{n, m}$ at hour $n$. If the capacitors are never used, the capacitor state at each stage will be always $X_{n, m}=\left[S_{1}(n), S_{2}(n), S_{3}(n), S_{4}(n)\right]=$ $(0,0,0,0)$ for $n=1,2, \ldots, 24$. The total feeder loss for the day is $966 \mathrm{~kW}$ in this case.

IEE PROCEEDINGS-C, Vol. 140, No. 6, NOVEMBER 1993 
As shown in Fig. 5, it is observed that the feeder loss is reduced from $966 \mathrm{~kW}$ in a day to $797 \mathrm{~kW}$, if each capacitor is allowed to be switched on once in a day. If the number of switching operations is increased to be 2 $(K=2)$, the loss will be further reduced to $780 \mathrm{~kW}$. To examine the effect of the number of capacitor switchings on feeder losses, cases with more than two switching operations $(K>2)$ are also investigated. The results are depicted in Fig. 6.

It is observed that feeder loss decreases with the increasing number of switching operations. In addition, the additional feeder loss reduction that can be achieved

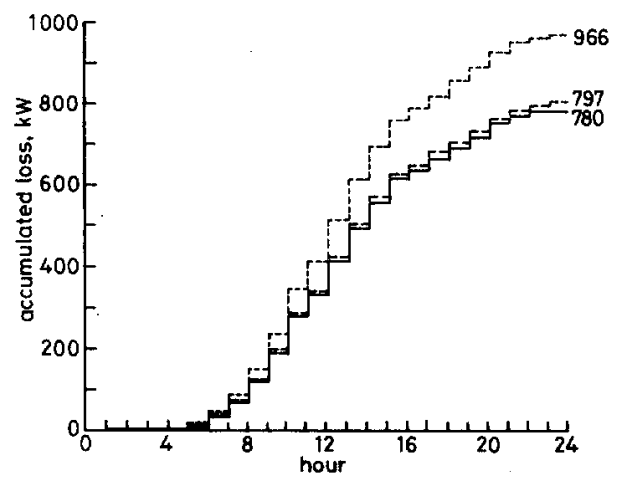

Fig. 5 The accumulated feeder losses for all capacitors are off $(K=0), K=1$, and $K=2$

-.. all off

$-K=1$

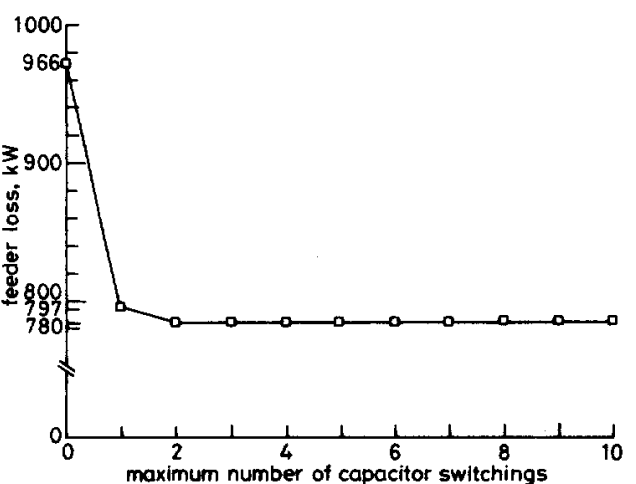

Fig. 6 The effect of the maximum number of capacitor switchings on feeder losses
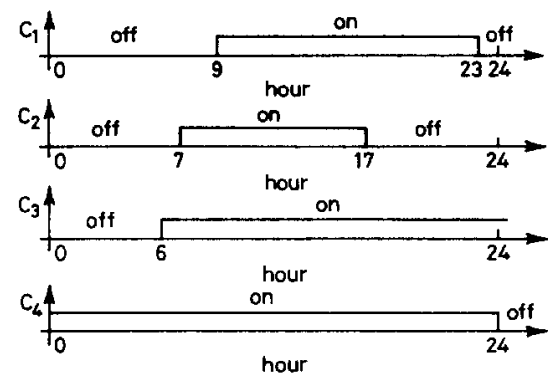

Fig. 7 The optimal capacitor dispatching schedule for the case of $K=2$ is very insignificant when the maximum number of switching operations exceeds $3(K>3)$. As frequency switching operations may decrease the life expectancy of the capacitor bank, and may cause transient voltages on the feeder, it seems proper to allow the capacitors to be switched twice a day at most for the system under study.

The optimal on/off status of each capacitor at each hour is depicted in Fig. 7 (see also Tables 4 and 5).

As the current practice at the Taiwan Power Company is to dispatch the capacitors on a fixed-schedule basis, it is desirable to compare the feeder loss of this fixedschedule capacitor dispatch with that of the proposed

Table 4: The optimal capacitor dispatching schedule and feeder losses for the cese of allowing each capacitor to be switched once $(K=1)$

\begin{tabular}{|c|c|c|c|}
\hline $\begin{array}{l}\text { Hour } \\
\text { (stage) } \\
n\end{array}$ & $\begin{array}{l}\text { State } \\
X_{n, m}= \\
{\left[S_{1}(n), S_{2}(n),\right.} \\
\left.S_{3}(n), S_{4}(n)\right]\end{array}$ & $\begin{array}{l}\text { Modified state } \\
X_{n}^{\prime}= \\
{\left[S_{1}^{\prime}(n), S_{2}^{\prime}(n)\right.} \\
\left.S_{3}^{\prime}(n), S_{4}^{\prime}(n)\right]\end{array}$ & $\begin{array}{l}\text { Loss } \\
P_{n}(k W)\end{array}$ \\
\hline $\begin{array}{r}1 \\
2 \\
3 \\
4 \\
5 \\
6 \\
7 \\
8 \\
9 \\
10 \\
11 \\
12 \\
13 \\
14 \\
15 \\
16 \\
17 \\
18 \\
19 \\
20 \\
21 \\
22 \\
23 \\
24\end{array}$ & $\begin{array}{l}(0,0,0,1) \\
(0,0,0,1) \\
(0,0,0,1) \\
(0,0,0,1) \\
(0,0,0,1) \\
(0,1,0,1) \\
(1,1,0,1) \\
(1,1,0,1) \\
(1,1,0,1) \\
(1,1,0,1) \\
(1,1,0,1) \\
(1,1,0,1) \\
(1,1,0,1) \\
(1,1,0,1) \\
(1,1,0,1) \\
(1,1,0,1) \\
(1,1,0,1) \\
(1,1,0,1) \\
(1,1,0,1) \\
(1,1,0,1) \\
(1,1,0,1) \\
(1,1,0,1) \\
(1,1,0,1) \\
(1,1,0,1)\end{array}$ & $\begin{array}{l}(0,0,0,1) \\
(0,0,0,1) \\
(0,0,0,1) \\
(0,0,0,1) \\
(0,0,0,1) \\
(0,1,0,1) \\
(1,1,0,1) \\
(1,1,0,1) \\
(1,1,0,1) \\
(1,1,0,1) \\
(1,1,0,1) \\
(1,1,0,1) \\
(1,1,0,1) \\
(1,1,0,1) \\
(1,1,0,1) \\
(1,1,0,1) \\
(1,1,0,1) \\
(1,1,0,1) \\
(1,1,0,1) \\
(1,1,0,1) \\
(1,1,0,1) \\
(1,1,0,1) \\
(1,1,0,1) \\
(1,1,0,1)\end{array}$ & $\begin{array}{r}1.171 \\
0.751 \\
0.944 \\
0.708 \\
2.825 \\
8.484 \\
21.971 \\
33.032 \\
53.471 \\
69.925 \\
89.363 \\
54.265 \\
83.784 \\
78.545 \\
66.177 \\
56.304 \\
22.883 \\
26.262 \\
28.887 \\
27.802 \\
32.977 \\
18.449 \\
11.403 \\
6.910\end{array}$ \\
\hline
\end{tabular}

Table 5: The optimal capacitor dispatching schedule and feeder losese for the case of allowing each capacitor to be awitched twice $(K=2)$

\begin{tabular}{llll}
\hline $\begin{array}{l}\text { Hour } \\
\text { (stage) }\end{array}$ & $\begin{array}{l}\text { State } \\
X_{n, m} \\
{\left[S_{1}^{\prime}(n), S_{2}(n),\right.}\end{array}$ & $\begin{array}{l}\text { Modified state } \\
X_{n, m}=\end{array}$ & $\begin{array}{l}\text { Loss } \\
{\left[S_{1}^{\prime}(n), S_{2}^{\prime}(n),\right.}\end{array}$ \\
& $P_{n}(\mathrm{~kW})$ \\
\hline 1 & $(0,0,0,1)$ & $(0,0,0,1)$ & 1.171 \\
2 & $(0,0,0,1)$ & $(0,0,0,1)$ & 0.751 \\
3 & $(0,0,0,1)$ & $(0,0,0,1)$ & 0.944 \\
4 & $(0,0,0,1)$ & $(0,0,0,1)$ & 0.708 \\
5 & $(0,0,0,1)$ & $(0,0,0,1)$ & 2.825 \\
6 & $(0,0,1,1)$ & $(0,0,1,1)$ & 8.476 \\
7 & $(0,1,1,1)$ & $(0,1,1,1)$ & 21.661 \\
8 & $(0,1,1,1)$ & $(0,1,1,1)$ & 33.155 \\
9 & $(1,1,1,1)$ & $(1,1,1,1)$ & 52.986 \\
10 & $(1,1,1,1)$ & $(1,1,1,1)$ & 68.623 \\
11 & $(1,1,1,1)$ & $(1,1,1,1)$ & 87.249 \\
12 & $(1,1,1,1)$ & $(1,1,1,1)$ & 53.761 \\
13 & $(1,1,1,1)$ & $(1,1,1,1)$ & 81.883 \\
14 & $(1,1,1,1)$ & $(1,1,1,1)$ & 76.868 \\
15 & $(1,1,1,1)$ & $(1,1,1,1)$ & 65.068 \\
16 & $(1,1,1,1)$ & $(1,1,1,1)$ & 55.683 \\
17 & $(1,0,1,1)$ & $(1,2,1,1)$ & 22.601 \\
18 & $(1,0,1,1)$ & $(1,2,1,1)$ & 26.128 \\
19 & $(1,0,1,1)$ & $(1,2,1,1)$ & 28.849 \\
20 & $(1,0,1,1)$ & $(1,2,1,1)$ & 27.733 \\
21 & $(1,0,1,1)$ & $(1,2,1,1)$ & 33.112 \\
22 & $(1,0,1,1)$ & $(1,2,1,1)$ & 17.965 \\
23 & $(0,0,1,1)$ & $(2,2,1,1)$ & 9.591 \\
24 & $(0,0,1,0)$ & $(2,2,1,2)$ & 2.525 \\
\hline
\end{tabular}


optimal eapacitor dispatch. Fig. 8 lists the feeder losses of both the fixed-schedule dispatch and the optimal dispatch. It is observed that greater loss reductions can be achioved by the proposed optimal capacitor dispatch than by the fixod-schedule capacitor dispatch.

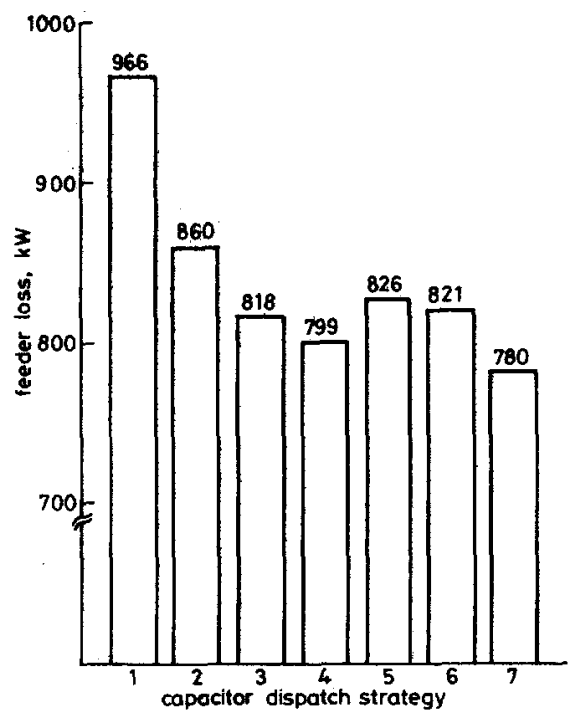

Fig. 8 Comparison of the feeder losses for the fixed-schedule capacitor dispatches and the proposed optimal capacitor dispatch

1 = all capacitors are of throwghout the day

2 - all capcitors are on throughout the day

$3=$ all capacitors are on from 7 a.m. to 6 p.m.

$4=$ all capacitors are on from 7 a.m. to 9 p.m.

5 - all capacitors are on from $8 \mathrm{am}$. to $5 \mathrm{pm}$.

7 = proposed optimal dimpatch $(K=2)$

\section{Conclusion}

An approach based on dynamic programming has been developed to determine the optimal dispatching schedule for capacitors on a distribution feeder in daily system operation. It is found that the total feeder losses in the study period ( 24 hours) can be reduced if the capacitors are dispatched according to the schedule achieved in this work. In addition, the proposed approach can yield a dispatching schedule that achieves a greater loss reduction than the fixed-schedule dispatch currently employed by the operators at the Taiwan Power Company. Another feature of the proposed method is that the number of switching operations in a day for each capacitor bank is limited, owing to the practical consideration of their life expectancies.

The proposed approach is rather efficient. It takes about $0.62 \mathrm{~s}$ to reach a solution on a VAX-11/8700 minicomputer. In the present work, only four capacitors are present on a feeder, and the computational complexity of the proposed approach depends mainly on the number of switchable capacitors on the feeder. The topology of the feeder and the locations of the switchable capacitors affect the solution time in computing the losses for the various states at each stage. If there are a great number of capacitors on a feeder, some simplifying procedures must be employed to reduce the storage requirement and CPU time. This is a feature of the dynamic programming approach.

A constant current model is employed here. To obtain a more accurate feeder loss, more elaborate load models may be used to replace the constant current model. The proposed method works equally well for different load models.

\section{References}

1 GONEN, T.: 'Electric power distribution system engineering' (McGraw-Hill, New York, 1986)

2 DURAN, H.: 'Optimum number, location, and size of shunt capacitors in radial distribution feeders: a dynamic programming approach', IEEE Trans. PAS, 1968, 87, pp. 1769-1774

3 LEE, S.H., and GRAINGER, JJ.: 'Optimum placement of fixed and switched capacitors on primary distribution feeders', IEEE Trans. $P A S, 1981,100$, pp. 345-352

4 GRAINGER, J., and LEE, S.H.: 'Optimum size and location of shunt capacitors for reduction of losses on distribution feeders', IEEE Trans. PAS, 1981, 1CA, pp. 1105-1118

5 GRAINGER, JJ., CIVANLAR, S., and LEE, S.H.: 'Optimal design and control scheme for continuous capacitive compensation of disand contral scheme for continuous capacitive compensation

6 GRAINGER, J.J., EL-KIB, A.A, and LEE, S.H.: 'Optimal capacitor placement on three-phase primary feeders: load and feeder unbalance effects', IEEE Trans. PAS, 1983, 102, pp. 3296-3305

7 PONNAVAIKKO, M., and PRAKASA RAO, K.S.: "Optimal choice of fixed and switched shunt capacitors on radial distributors by the method of local variations', IEEE Trans. PAS, 1983, 102, pp. $1607-1614$

8 FAWZI, T.H., EL-SOBKI, S.M, and ABDEL-HALIM, M.A.: 'New approach for the application of shunt capacitors to the primary distribution feeder', IEEE Trans. PAS, 1983, 102, pp. 10-13

9 KAPLAN, M.: 'Optimization of number, location, size, control type, and control settings of shunt capacitors on radial distribution foeders', IEEE Trans. PAS, 1984, 192, pp. 2659-2663

10 GRAINGER, JJ, and CIVANLAR, S.: Volt/Var control on distribution systems with lateral branches using shunt capacitors and voltage regulators', IEEE Trans. PAS, 1985, 104, pp. 3278-3297

11 BISHOP, M.T., and LEE, R.E.: Distribution system line loss reduction through enhanced capacitor location techniques', IEEE Trans. Power De, 1986, PWRD-1, pp. 190-197

12 BARAN, M.E., and WU, F.F.: 'Optimal capacitor placement on radial distribution systems;, Paper 88 WM 064-8, presented at the IEEE/PES 1988 Winter Meeting

13 BARAN, M.E., and WU, F.F.: 'Optimal sizing of capacitors placed on a radial distribution system;, Paper 88 WM $065-5$, presented at the IEEE/PES 1988 Winter Meeting

14 BAGHZOUZ, Y.: 'Effects of nonlinear loads on optimal capacitor placement in radial feeders', IEEE Trans. Power De., 1991, PWRD-6, pp. 245-251

15 RIZY, D.T. LAWLER, J.S., PATTON, J.B., and FORTSON, N.H. 'Distribution automation applications woftware for the Athens Utilities Board', IEEE Trans. Power De., 1989, PWRD-4, pp. 714-723

16 RIZY, D.T. LAWLER, J.S., PATTON, J.B., and NELSON, W.R. Measuring and analyzing the impact of voltage and capacitor control with high speed data acquisition', IEEE Trans. Power De., 1989, PWRD-4, pp. 704-714

17 SANTOSO, N.I., and TAN, O.T: 'Neural-net based real-time control of capacitors installed on distribution systems', IEEE Trans. Power De., 1990, PWRD-5, pp. 266-272

18 HO, K.L., HSU, Y.Y., CHEN, C.F., LEE, T.E., LIANG, C.C., LAI, T.S., and CHEN, K.K.: Short-term load forecasting of Taiwan power system using a knowledge-based expert system', IEEE Trans. Power Syst., 1990, 5, pp. 1214-1221

19 GROSS, G., and GALIANA, F.D.: 'Short-term load forecasting', Proc. IEEE, 1987, 75, No. 12, pp. 1558-1573 